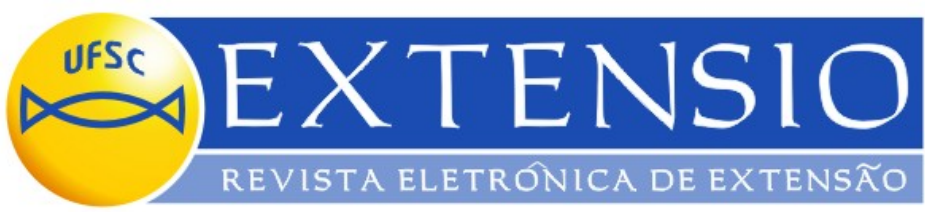

\title{
CUIDADO À SAÚDE BUCAL DE IDOSOS INSTITUCIONALIZADOS EM FLORIANÓPOLIS: APROXIMANDO ENFERMAGEM E ODONTOLOGIA
}

\author{
Fernanda Amorim \\ Acadêmica do Curso de Odontologia, UFSC \\ Ana Lúcia S. Ferreira de Mello \\ Doutora em Enfermagem, UFSC \\ Renata Goulart Castro \\ Mestre em Odontologia em Saúde Coletiva, UFSC \\ Cláudio José Amante \\ Professor do Departamento de Estomatologia, UFSC \\ Alacoque Lorenzini Erdmann \\ Professora do Departamento de Enfermagem, UFSC (coordenadora) \\ alacoque@newsite.com.br
}

\section{Resumo}

Este trabalho teve como objetivo principal promover a saúde bucal de pessoas idosas residentes nas instituições SERTE e SEOVE por meio do estabelecimento de um protocolo de cuidado à saúde bucal, compartilhando e aplicando conhecimentos de Enfermagem e Odontologia. Inicialmente, foram avaliadas as condições dos elementos dentários, gengiva, mucosa e de próteses. Após o reconhecimento das condições de saúde e higiene bucal dos idosos, foi realizado o levantamento das suas respectivas necessidades de cuidado à saúde bucal e implantação do protocolo individual de cuidados. Após três meses de aplicação, as condições de higiene bucal foram reavaliadas. Não se percebeu diminuição na quantidade de placa nos dentes e próteses, embora tenha havido leve diminuição na quantidade de placa não sensível ao exame clínico. Entretanto, houve melhora do grau de inflamação da mucosa oral. Durante a execução do projeto, conseguiu-se manter a realização de um protocolo de higiene bucal semanal e realizar atendimento clínico odontológico em idosos, passando-se a estender o serviço aos empregados de uma das instituições.

Palavras-chave: Cuidado à saúde. Idoso. Saúde Bucal. 


\title{
ORAL HEALTH CARE FOR INSTITUTIONALIZED ELDERLY PEOPLE IN FLORIANÓPOLIS: GATHERING NURSING AND DENTAL AREAS
}

\begin{abstract}
The aim of this work was to promote the oral health of elderly people living in two long term care institutions SERTE and SEOVE through the establishment of an oral care protocol, sharing and applying knowledges of Nursing and Dentistry areas. Initially, it was analyzed the conditions of teeth, gums, oral mucosa and prostheses of the elderly. After this recognition, it was defined the respective oral care needs and it was established and implemented an individual protocol. After three months of application of the protocol, the oral hygiene conditions were revalued. Decrease in the amount of plaque in the teeth and prostheses were not noticed, although it has had a light decrease in the amount of plaque, non sensitive to the clinical exam. However, there was an improvement on the degree of oral mucosa inflammation. During the execution of the project, it was possible to maintain the accomplishment of a protocol of weekly oral hygiene and to accomplish dental attendance for the elders, starting to extend the oral attendance to the employees of one of these institutions.
\end{abstract}

Keywords: Health Care. Elderly. Oral Health.

\section{Introdução}

Este projeto deu continuidade ao trabalho de extensão universitária, iniciado em 2003, sob os auspícios do Pró-Extensão e procurou levar melhores práticas de cuidado à saúde bucal a pessoas idosas portadoras de necessidades especiais que vivem em instituições geriátricas filantrópicas em Florianópolis. Em face das parcerias positivas com as respectivas instituições, o trabalho prosseguiu na Sociedade Espírita de Recuperação, Trabalho e Educação (SERTE) e na Sociedade Espírita Obreiros da Vida Eterna (SEOVE). Além do trabalho voluntário de cirurgiões-dentistas, contou-se com o apoio de um estagiário bolsista, aluno de Odontologia, para o cumprimento de tarefas do seu campo de conhecimento. Além disso, o projeto buscou compartilhar e aplicar saberes próprios da Enfermagem.

Anteriormente, com os recursos do Pró-Extensão, foram adquiridos materiais odontológicos, permanentes e de consumo, e material bibliográfico. Também foram 
viabilizadas a editoração e impressão de um Manual intitulado Melhores práticas no cuidado à saúde bucal de idosos, especialmente dirigido a cuidadores de idosos. Assim, o trabalho de extensão realizado na SERTE e na SEOVE gerou a segurança para a difusão de valiosos conhecimentos capazes de melhorar a saúde bucal dos idosos.

Apesar de o processo de envelhecimento ter poucos efeitos desencadeadores de disfunções e incapacidades relacionadas à cavidade bucal, a população idosa apresenta uma condição de saúde bucal precária (COLUSSI; FREITAS, 2002).

Nas instituições onde este projeto foi aplicado, foi constatada uma deficiente condição bucal entre os idosos analisados. Os dados referentes ao estado dentário demonstraram um CPO-D ${ }^{1}$ médio de 28,1 , formado principalmente pelo componente perdido $(27,4)$. Já as lesões de mucosa mais prevalentes pertenciam aos grupos de hiperplasias e candidíases (MELLO; CASTRO; OLEINISKI, 2003).

Em estudo realizado em instituições de longa permanência para idosos de Porto Alegre, Mello (2001) revelou o cuidado à saúde bucal prestado como muito insatisfatório; isto pela característica empírica dos procedimentos de higiene bucal realizados, desassociados de adequada orientação técnica, especialmente odontogeriátrica, e envolvidos num ambiente de descompromisso organizacional privado, institucional público, e até familiar. Esse cenário sugere que muitos residentes em instituições de longa permanência para idosos podem estar sendo negligenciados permanentemente no âmbito da sua saúde bucal, pela falta de oportunidade de diagnóstico, pela fragilidade das ações de cuidado diário, pela não valorização das ações preventivas a esse grupo populacional, e pela pouca disponibilidade de acesso a tratamento curativo e reabilitador.

As doenças cárie e periodontal são as mais prevalentes na cavidade bucal, ambas possuem como fator etiológico determinante a placa dentária. Portanto, a sua remoção é uma das medidas mais direta e abrangente de controle e tratamento dessas patologias. A higiene bucal é parte fundamental dos cuidados necessários para a manutenção da saúde bucal dos indivíduos. Dentre os métodos de controle mecânico da placa estão a escovação dentária com dentifrício, a limpeza interproximal com fio/fita dental ou escovas interproximais e agentes evidenciadores de placa, os quais promovem a visualização das zonas de acúmulo de placa pelo indivíduo (BUISCHI; AXELSSON, 1997).

\footnotetext{
${ }^{1} \mathrm{O}$ índice CPO-D é a soma dos dentes permanentes acometidos pela doença cárie dental (cariados, perdidos por cárie ou restaurados por cárie). Os valores em um indivíduo podem ser de 0 a 32 . Os dados populacionais referem-se à média dos valores individuais.
} 
A utilização de agentes químicos para o controle da placa dental pode ser justificada pela dificuldade em se manter um adequado controle mecânico pelo indivíduo, bem como pela origem bacteriana das duas principais patologias bucais (CURY, 1997).

O gluconato de clorexidine é o mais testado e efetivo agente microbiano utilizado na cavidade bucal para o controle químico da placa bacteriana. Ele inibe sua formação e, possuindo ação antiséptica, anticáries, antiplaca, reverte quadros de gengivite. Possui absorção seletiva pelos tecidos orais incluindo dentes e subsequente liberação gradual mantendo sua atividade antimicrobiana (LOE, 2000). As concentrações indicadas variam entre $0,12 \%$ e $0,2 \%$ nas soluções para bochecho ou 1\% em forma de gel. Alguns efeitos colaterais podem ser observados, os mais frequentes são o manchamento de dentes e língua e alterações no paladar (MONTENEGRO, BRUNTETTI, 2002).

Num grande número de indivíduos idosos, chega-se a reversão de problemas periodontais, com sequelas mínimas, por meio da redução microbiana e controle da higiene bucal (HAUGEN, 1992).

Alguns autores sugerem que pessoas idosas acreditam poder realizar sua higiene bucal apropriadamente, mas não estão cientes de suas limitações e do pouco efeito de seus esforços. Assim como em qualquer tratamento, o profissional deve ter em mente a tríade: prevenção do início da doença, da progressão e da recorrência, não apenas para cárie e doença periodontal, mas também para defeitos bucais e maloclusão, lesões pré-cancerosas e cancerosas e doenças sistêmicas com manifestações bucais. Para isso, devem-se considerar dados epidemiológicos, a função bucal em idosos e os mecanismos de prevenção (MANDEL, 1993).

Este trabalho teve como objetivo principal promover a saúde bucal de pessoas idosas residentes nas instituições citadas por meio do estabelecimento de um protocolo de cuidado à saúde bucal individualizado e permanente, compartilhando e aplicando conhecimentos de Enfermagem e Odontologia.

\section{Material e Métodos}

Este projeto foi desenvolvido nas residências geriátricas da SERTE e da SEOVE, ambas localizadas em Florianópolis, SC, entre os meses de maio a dezembro de 2005. Residiam na SERTE, naquela época, 47 idosos e na SEOVE 25 idosas.

Inicialmente, foi realizado um levantamento das condições de saúde bucal de todos os idosos, visando a atualização de dados já existentes e cadastramento das condições bucais de 
novos idosos residentes. Foram avaliadas a condição dos elementos dentários, gengiva, mucosa e utilização de próteses.

Após o reconhecimento das condições de saúde bucal, foi realizado levantamento das respectivas necessidades de cuidado à saúde bucal. Foram avaliados os procedimentos realizados e sua frequência, materiais necessários e necessidade de auxílio para a higiene bucal. Para os 34 idosos que possuíam dentes e/ou próteses, foi realizado um levantamento da quantidade de placa nas superfícies dentárias e protéticas e a avaliação do grau de inflamação da mucosa bucal. Os critérios de exame utilizados encontram-se nos quadros Quadro 1, Quadro 2 e Quadro 3 (SILNESS; LÖE, 1963; AMBJORNSEN et al. 1982; HENRIKSEN; AMBJORNSEN; AXELL, 1999).

\begin{tabular}{|l|l|l|}
\hline \multicolumn{2}{|c|}{ Critérios para avaliação dos elementos dentários } \\
\hline $\mathbf{0}$ & Sem placa visível & $\begin{array}{l}\text { Ausência de placa visível sobre as superfícies } \\
\text { dentais }\end{array}$ \\
\hline $\mathbf{1}$ & Pequena quantidade de placa visível & $\begin{array}{l}\text { Até } 1 / 3 \text { das superfícies dentais cobertas por } \\
\text { placa }\end{array}$ \\
\hline $\mathbf{2}$ & Moderada quantidade de placa visível & $\begin{array}{l}\text { Até } 2 / 3 \text { das superfícies dentais cobertas por } \\
\text { placa }\end{array}$ \\
\hline 3 & Abundante quantidade de placa visível & $\begin{array}{l}\text { Mais de } 2 / 3 \text { das superfícies dentais cobertas } \\
\text { por placa }\end{array}$ \\
\hline
\end{tabular}

Quadro 1: Critérios para avaliação dos elementos dentários

Fonte: Adaptado de Silness; Löe, 1963.

\begin{tabular}{|l|l|l|}
\hline \multicolumn{2}{|c|}{ Critérios para avaliação das próteses dentárias } \\
\hline 0 & Sem placa visível & $\begin{array}{l}\text { Ausência de placa visível sobre as próteses } \\
\text { dentárias }\end{array}$ \\
\hline 1 & Pequena quantidade de placa visível & $\begin{array}{l}\text { Até } 1 / 3 \text { da superfície das próteses cobertas } \\
\text { por placa }\end{array}$ \\
\hline 2 & Moderada quantidade de placa visível & $\begin{array}{l}\text { Até } 2 / 3 \text { das superfícies das próteses cobertas } \\
\text { por placa }\end{array}$ \\
\hline 3 & Abundante quantidade de placa visível & $\begin{array}{l}\text { Mais de } 2 / 3 \text { das superfícies das próteses } \\
\text { cobertas por placa }\end{array}$ \\
\hline
\end{tabular}

Quadro 2: Critérios para avaliação das próteses dentárias

Fonte: Adaptado de Ambjornsen et al.; 1982.

\begin{tabular}{|c|l|l|}
\hline \multicolumn{2}{|c|}{ Critérios para avaliação da mucosa bucal } \\
\hline $\mathbf{0}$ & Normal & Aparência normal das gengivas e mucosa \\
\hline $\mathbf{1}$ & Inflamação leve & $\begin{array}{l}\text { Leves alterações de cor ou forma das } \\
\text { gengivas e/ou áreas levemente avermelhadas } \\
\text { da mucosa queratinizada }\end{array}$ \\
\hline $\mathbf{2}$ & Inflamação moderada & $\begin{array}{l}\text { Gengivas marcadamente avermelhadas ou } \\
\text { edemaciadas e de fácil sangramento quando } \\
\text { pressionadas e/ou áreas marcadamente } \\
\text { avermelhadas da mucosa queratinizada, } \\
\text { úlceras ou hiperplasias causadas por próteses }\end{array}$ \\
\hline
\end{tabular}


3

Inflamação severa
Avermelhamento ou edema severo das gengivas, sangramento espontâneo das gengivas, avermelhamento ou edema severo do palato, hiperplasias inflamatórias

Quadro 3: Critérios para avaliação da inflamação na mucosa

Fonte: Adaptado de Henriksen; Ambjornsen; Axell, 1999.

A etapa seguinte foi o planejamento e a implantação, em regime de protocolo, dos procedimentos semanais de higiene bucal, orientado na aplicação de melhores práticas em saúde bucal para os 34 idosos residentes que possuíam dentes e/ou próteses em uso. Esta etapa contou com a participação da equipe de Enfermagem das instituições participantes (auxiliares, técnicos e enfermeiros).

O protocolo, respeitando a necessidade individual de cada idoso, incluía higienização de dentes e próteses removíveis, desinfecção de próteses, administração de anti-séptico clorexidine $0,12 \%$, aplicação tópica de flúor, motivação para autocuidado à saúde bucal e auxílio para procedimentos de higiene bucal, sendo realizado com frequência semanal pela estagiária-bolsista. Para tanto, foi preparada uma unidade móvel de higienização ilustrada na Figura 1, a qual possuía as escovas dentais dos idosos devidamente identificadas, sacos plásticos para acondicionamento das escovas, solução de clorexidine $0,12 \%$, copinhos descartáveis pequenos, dentifrício fluoretado, gel de flúorfosfatoacidulado $1,23 \%$, recipientes para acondicionamento das próteses removíveis devidamente identificados, aspirador cirúrgico elétrico, sugadores descartáveis, gaze, guardanapos de papel, ficha controle de higienização, caneta para anotação e luvas de procedimento.

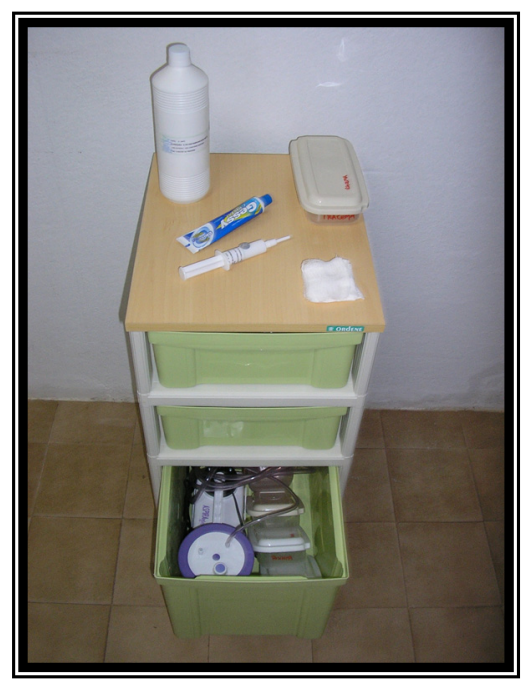

Figura 1: Unidade móvel de higienização 
Os idosos eram abordados pela estagiária para a aplicação do protocolo de maneira individual. Aqueles que rotineiramente realizavam sozinhos os cuidados bucais eram encaminhados à pia do seu respectivo banheiro/quarto, onde a estagiária-bolsista acompanhava a realização da higienização dos dentes e/ou das próteses removíveis, estimulando o autocuidado, e auxiliando quando necessário. Para a escovação dentária e para a escovação das próteses removíveis dentifrício (Figura 2), era utilizado o gel de fluorfosfato acidulado $1,23 \%$ pelo tempo de 1 minuto.

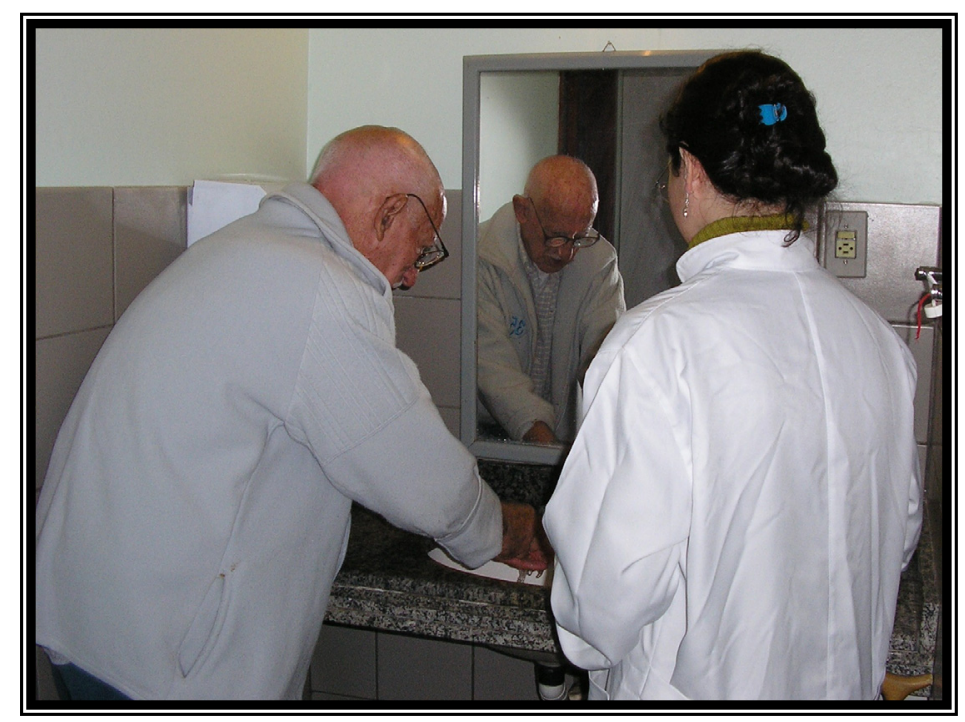

Figura 2: Acompanhamento da higienização

Após esta etapa, o idoso era reavaliado (Figura 3) e, caso necessário, repetia-se o procedimento. Partia-se então para a aplicação de um bochecho com solução de clorexidine $0,12 \%$ pelo tempo de 1 min, e imersão das próteses em solução de clorexidine $0,12 \%$ por 1 min para desinfecção. 


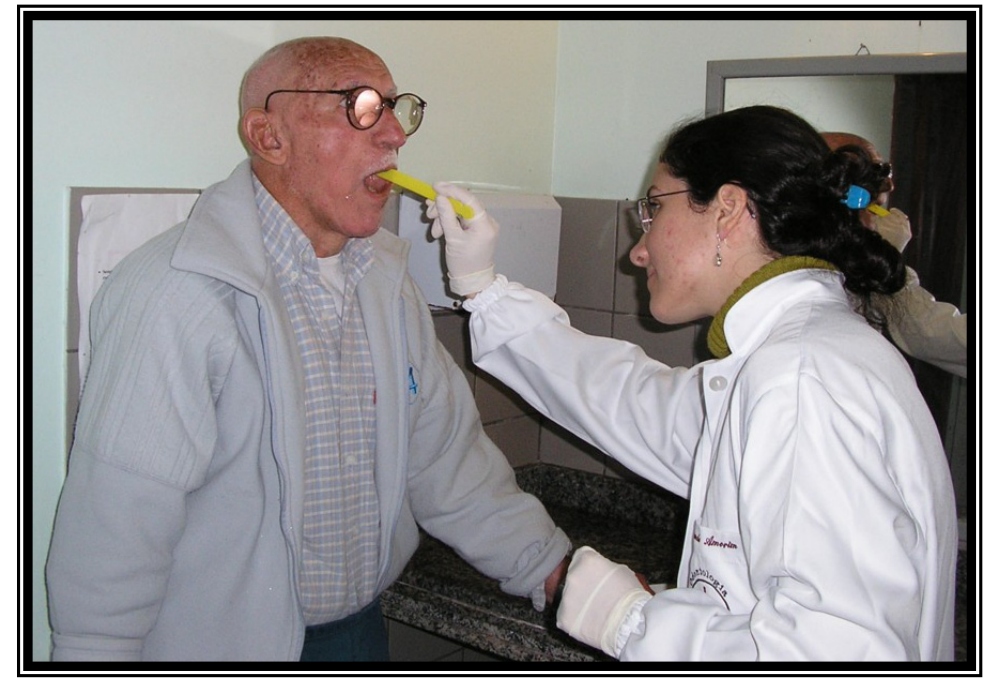

Figura 3: Avaliação durante a higienização

Nos casos dos idosos dependentes que não conseguiam realizar sozinhos os cuidados bucais, os procedimentos eram realizados pela estagiária-bolsista, a qual procedia primeiramente com a higienização dos dentes, depois fazia a escovação das próteses, a realização de bochecho, quando esta era inviável, a solução era aplicada com gaze e a desinfecção das próteses.

Durante a higienização, os idosos com acúmulo de tártaro nos elementos dentários eram encaminhados ao cirurgião-dentista responsável para a realização de tartarectomia com ultrassom.

Após a higienização, as escovas eram limpas em água corrente e desinfetadas em solução de clorexidine.

Ao final do projeto, foi realizado novo exame clínico, seguindo os critérios iniciais para avaliação de placa dentária e em próteses, para possibilitar a avaliação da evolução da condição de higiene bucal.

A estagiária-bolsista acompanhou na SERTE, onde havia consultório odontológico, as atividades de assistência clínica odontológica junto aos profissionais. Foram realizados procedimentos de remoção de tártaro com ultrassom, confecção de próteses removíveis e exodontias. Ao final do projeto, ampliou-se o atendimento clínico odontológico para os profissionais de Enfermagem cuidadores e empregados da instituição SERTE. 


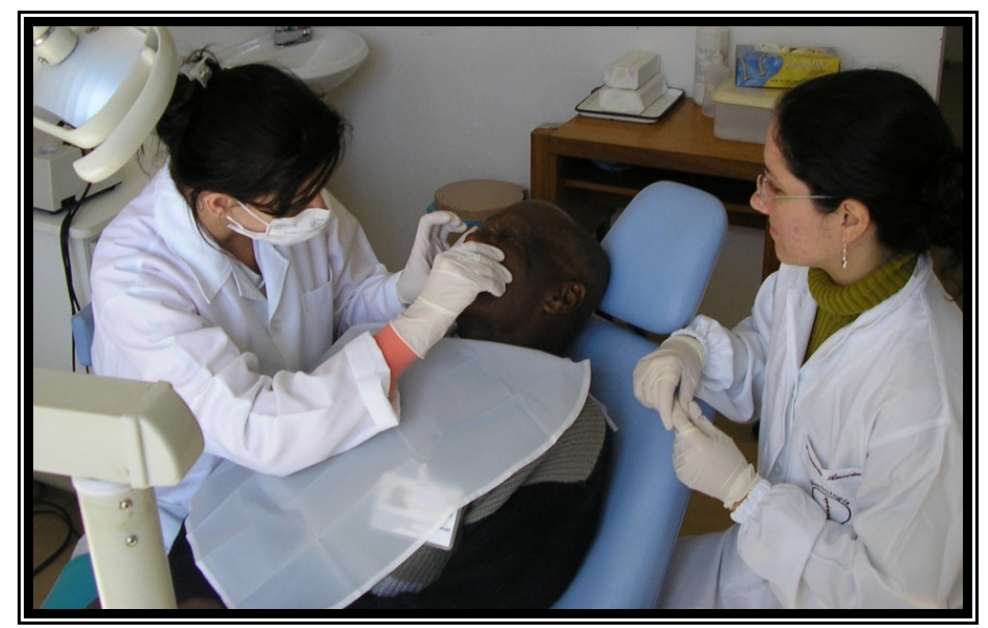

Figura 4: Atendimento clínico com auxílio da estagiária-bolsista

\section{Resultados e Análise}

O protocolo de higiene bucal semanal foi implantado nas instituições participantes e possibilitou a troca de conhecimentos próprios entre Odontologia e Enfermagem, num trabalho interdisciplinar com o compartilhamento de experiências no ambiente das residências geriátricas.

Dentre os 34 idosos participantes, 24 eram mulheres e, destas, 9 residiam na SEOVE, instituição que só atende a mulheres. Não puderam ser examinados, ao final, 2 idosos no exame das próteses e 5 idosos no exame de mucosa por motivo de falecimento, hospitalização ou problemas de saúde.

Os dados avaliados ao início e ao final da implantação do protocolo de higiene bucal estão apresentados nas tabelas 1 e 2 .

Tabela 1: Avaliação inicial da presença da placa bacteriana em dentes e prótese e níveis de inflamação da mucosa bucal

\begin{tabular}{|c|c|c|c|c|c|}
\hline \multicolumn{2}{|c|}{ Dentes } & \multicolumn{2}{|c|}{ Próteses } & \multicolumn{2}{|c|}{ Mucosa bucal } \\
\hline $\begin{array}{l}\text { Quantidade de } \\
\text { placa visível }\end{array}$ & $N^{0}$ idosos & $\begin{array}{l}\text { Quantidade de } \\
\text { placa visível }\end{array}$ & $\mathbf{N}^{0}$ idosos & $\begin{array}{c}\text { Nível de } \\
\text { Inflamação }\end{array}$ & $\mathrm{N}^{\mathbf{0}}$ idosos \\
\hline Sem & 0 & Sem & 4 & Sem & 10 \\
\hline Pequena & 12 & Pequena & 7 & Leve & 18 \\
\hline Moderada & 2 & Moderada & 8 & Moderada & 5 \\
\hline Abundante & 3 & Abundante & 1 & Severa & 1 \\
\hline Total & 17 & Total & 20 & Total & 34 \\
\hline
\end{tabular}

Fonte: Elaborada pelos autores, 2008. 
Tabela 2: Avaliação final da presença da placa bacteriana em dentes e prótese e níveis de inflamação da mucosa bucal.

\begin{tabular}{|c|c|c|c|c|c|}
\hline \multicolumn{2}{|c|}{ Dentes } & \multicolumn{2}{|c|}{ Próteses } & \multicolumn{2}{|c|}{ Mucosa bucal } \\
\hline $\begin{array}{l}\text { Quantidade de } \\
\text { placa visível }\end{array}$ & $\mathbf{N}^{0}$ idosos & $\begin{array}{l}\text { Quantidade de } \\
\text { placa visível }\end{array}$ & $\mathrm{N}^{0}$ idosos & $\begin{array}{c}\text { Nível de } \\
\text { Inflamação }\end{array}$ & $N^{0}$ idosos \\
\hline Sem & 1 & Sem & 6 & Sem & 22 \\
\hline Pequena & 8 & Pequena & 6 & Leve & 3 \\
\hline Moderada & 6 & Moderada & 6 & Moderada & 3 \\
\hline Abundante & 2 & Abundante & 0 & Severa & 1 \\
\hline Total & 17 & Total & 18 & Total & 29 \\
\hline
\end{tabular}

Fonte: Elaborada pelos autores, 2008.

Não se percebeu diminuição na quantidade de placa nos dentes e próteses, embora tenha havido leve diminuição na quantidade de placa não sensível ao exame clínico proposto. Entretanto, houve melhora do grau de inflamação da mucosa oral. Outro achado importante foi que, apesar de ainda haver quantidade de placa considerável nos dentes e próteses, com a evolução da aplicação do protocolo, pôde-se observar uma maior facilidade na remoção da placa bacteriana, além da constatação da diminuição nos níveis de halitose ao final do projeto.

\section{Considerações Finais}

De modo geral, conseguiu-se cumprir o cronograma de atividades estabelecidas no projeto a contento. Todas as etapas foram realizadas, atingindo-se o objetivo de aproximar saberes e experiências profissionais da Enfermagem e da Odontologia para o cuidado à saúde bucal dos idosos. Durante a execução do projeto, conseguiu-se manter a realização de um protocolo individualizado de higiene bucal semanal e realizar atendimento clínico odontológico em idosos, passando-se a estender o serviço aos empregados de uma das instituições.

Recomenda-se reforçar a necessidade da incorporação de procedimentos de higiene bucal na rotina de cuidados à saúde dos idosos, bem como capacitação e treinamento dos cuidadores para a aplicação de protocolos de higiene bucal, a continuidade na troca de experiência e saberes da Enfermagem e da Odontologia em prol da aplicação de melhores práticas de cuidado à saúde bucal de idosos institucionalizados, e a consideração do ambiente das residências geriátricas como espaço de aprendizagem teórico-prática para acadêmicos da Enfermagem e da Odontologia. 


\section{Referências}

AMBJORNSEN, E. et al. Assessment of an additive index for plaque accumulation on complete maxillary dentures. Acta Odontol. Scand., Oslo, Aug. 1982. v. 40, n.4, p.203-208.

BUISCHI, Y. P., AXELSSON, P. Controle mecânico da placa dental realizado pelo paciente. In: Promoção de saúde bucal - ABOPREV. Artes Médicas: São Paulo. 1997. cap. 6, p. 113128.

COLUSSI, C.F.; FREITAS, S.F.T. Aspectos epidemiológicos da saúde bucal do idoso no Brasil. Cad. Saúde Pública, Rio de Janeiro, out. 2002, v.18, n.5, p.1313-1320.

CURY, J. Controle químico da placa dental. In: Promoção de saúde bucal - ABOPREV. Artes Médicas: São Paulo. 1997. cap. 7. p. 129-140.

HAUGEN, L.K. Biological and physical changes in the ageing individual. Int Dent J v.42, n.5, p.339-48, Oct, 1992.

HENRIKSEN, B.M.; AMBJORNSEN, E.; AXELL, T.E. Evaluation of a mucosal-plaque index (MPS) designed to assess oral care in groups of elderly. Spec Care Dentist. v. 19, n. 4, p. 154-157, Jul/Aug. 1999.

LOE, H. Oral hygiene in the prevention of caries and periodontal diseases. Int Dental Journal, v. 50, n. 3, p.129-139, 2000.

MANDEL, I.D. Preventive dentistry for the elderly. Spec Care Dent. v.3, n.4, p.157-163, Jul/Ago. 1993.

MELLO, A. L. S. F.; CASTRO, R. C.; OLEINISKI, J. C. Condições de saúde bucal de idosos residentes em instituições filantrópicas em Florianópolis (SC). Pesq. Odontol. bras., São Paulo, v. 17, p. 31, ago. 2003. Suplemento 2

MELLO, A.L.S.F. Cuidado à saúde bucal provido a idosos residentes em instituições geriátricas de pequeno porte em Porto Alegre - RS: a retórica, a prática e os resultados. Dissertação (Mestrado em Saúde Bucal Coletiva) - Faculdade de Odontologia, Universidade Federal do Rio Grande do Sul, Porto Alegre, 2001.

MONTENEGRO, L. F. B.; BRUNTETTI, R. Higienização do idoso com reabilitações bucais. In: Odontogeriatria: noções de interesse clínico. Artes Médicas: São Paulo. 2002. cap. 18. p. 
EXTENSIO: Revista Eletrônica de Extensão

Ano $6 \cdot$ n. 7 • Julho de 2009 $\bullet$ ISSN: 1807-0221

$335-359$.

SILNESS, J.; LÖE, H. Periodontal disease in pregnancy II: correlation between oral hygiene and periodontal condition. Acta Odontol. Scand., Oslo, v.22, n.2, p. 121-135, Fev. 1963. 